\title{
I LOVE SCIENCE IN MANY FORMS
}

\author{
Laureate of the Nobel Prize in Chemistry 2014 William E. Moerner talks
}

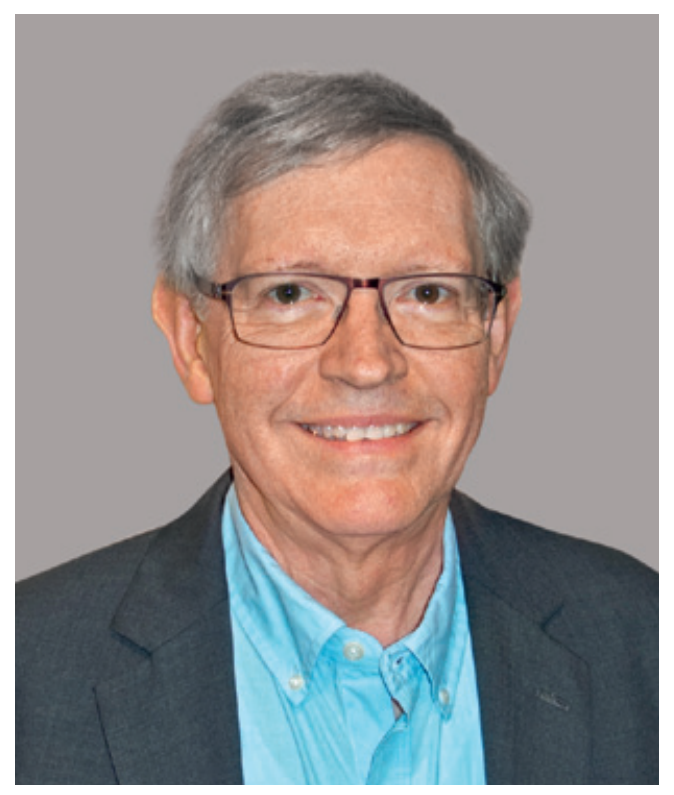

The 2014 Nobel Prize in Chemistry was awarded for the development of super-resolution fluorescence microscopy, which enables the imaging of fine biological structures, previously thought to be unresolvable, using light. "This year's prize is about how the optical microscope became a nanoscope" announced Staffan Normark, the permanent secretary of the Royal Swedish Academy of Sciences. Stefan Hell (Max Planck Institute for Biophysical Chemistry, Göttingen, Germany), William Moerner (Stanford University in California, USA) and Eric Betzig (Howard Hughes Medical Institute in Virginia, USA) laid the foundations for powerful new microscopes that are used to study tissues at the level of single molecules.

From 1998 until the present, W.E. Moerner has been working at Stanford University in California, where he leads a laboratory conducting research on biological processes at the level of a single molecule.

In the exclusive interview with our magazine, William E. Moernertalksabout thefundamental principles and astonishing possibilities of the single-molecule fluorescent microscopy.

You received the Nobel Prize "for the development of super-resolved fluorescence microscopy". What is the essence of this method?

When you image something with an optical microscope you collect light that is produced by the sample. One has to ask: how good can the resolution be, or, in other words, what is the smallest distance between the objects that can be detected. The basic problem is that in conventional far-field microscopes, the resolution is limited by the Abbe fundamental diffraction limit, which is approximately equal to half the wavelength $\lambda$ used for irradiation. In accordance with this principle, the resolution of light microscopy cannot be smaller than about $250 \mathrm{~nm}$ with visible light. This means that any optical image, even if it is a single molecule, will look like a spot with a diameter of $250 \mathrm{~nm}$. Even when the actual size of the object is $1 \mathrm{~nm}$, it still looks that big. A virus, a protein, and a really small molecule - all of them will look the same in a traditional light microscope. The key idea of super-resolution is to go beyond the diffraction limit. Today we can overcome the diffraction barrier to get the resolution down to $20 \mathrm{~nm}$ and see fine details ten times smaller or more. Some neat techniques even go down to $1 \mathrm{~nm}$, but more regularly the resolution is about $10 \mathrm{~nm}$.

Of course, there are electron and x-ray techniques with much higher resolution. The electron microscope images objects in cells with near-atomic resolution to see the shape of a molecule. However, it doesn't allow us to 
study living cells or the processes occurring within them You have to kill a living object, slice it, fixate it and subject it to intense radiation in a high vacuum. In contrast to electron microscopy, the point of light microscopy isn't to look at individual atoms in a molecule. Light possesses the least invasiveness compared to other methods and doesn't damage the biological tissue. Unlike the beam of electrons, light can be used to noninvasively probe a sample with relatively small perturbation of the specimen, which is why the optical fluorescence microscope is such an important instrument for cell biology. Moreover, it enables one to not only make static snapshots but also to observe the motions of internal structures in living cells.

Besides, there is another advantage. Usually chemists deal with a large ensemble of molecules and measure the average of some parameter over millions or billions of copies. However, each molecule may have a different behavior, and this heterogeneity cannot usually be sensed. When we look into a cell, we are mostly interested in a certain kind of protein or another biomolecule, and we have to make this species distinct from the rest-we have to select them from other molecules. In light microscopy, this can be done by attaching a fluorescent molecule or label to the biomolecule of interest. The minimum size of the studied object is the size of the fluorophore itself, which is about 1 to $2 \mathrm{~nm}$. Using super-resolved fluorescent microscopy we can observe a single molecule hidden deep within a crystal, polymer, or cell in the presence of billions to trillions of solvent or host molecules. Any object can be examined: a cell membrane, an antibody, a primary cilium, a protein. You can learn more about the fundamental processes inside the cells, about the behavior of proteins, DNA, etc. by observing individuals rather than averages.

\section{How is the experiment conducted and what kind of information about the molecule do you get?}

In most experiments we attach small fluorophores to bigger objects such as a protein, and this fluorophore tells us where this object is located to a precision of about $10 \mathrm{~nm}$. Then we can track the molecule: how it moves, what it does and so on. When the concentration of labeled molecules is kept low, only one molecule is pumped at a time, and we can figure out the precise position of the molecule even though the focal spot is much bigger than the size of a fluorophore. To do that we perform the super-localization process that allows us to determine the position of the emitter by fitting the shape of the single-molecule image. For example, we were able to obtain the positions of single $\mathrm{MHCI}$ (major histocompatibility complexes of type II) proteins anchored in the plasma membrane of a Chinese hamster ovary cell. A high-affinity antigenic peptide was labeled with a single fluorophore to light up the MHCII molecules, and a real-time fluorescence video of the motion of these molecules showed the amazing dance of MHCII's which occurs on the surface of live cells. The diffusive properties of the motion and the influence of cholesterol were studied by my students in collaboration with Harden McConnell'.

Let me give you another example. The centriole - a critical component involved in cell division - has a tubular structure $250 \mathrm{~nm}$ in diameter. At the top of a centriole, there is a set of proteins, one of which is called CEP164. Due to binding with specific receptors on the surface this protein can localize in 9 distinct clusters spaced around a ring of $\sim 300 \mathrm{~nm}$ in diameter. However, when looking through a conventional light microscope you can only observe a blurry image. The emergence of superresolution microscopy allows us to clearly see these nine bright spots².

Tracking the molecules in a cell is one of the applications of fluorescence microscopy. Another is the imaging of the object structure.

Suppose you have extended structure, for example, a microtubule. All cells have these microtubules as a part of their skeleton. A microtubule is a long thin object composed of many copies of the molecule tubulin bound in a filament, with its width being 10-50 nanometers, and the length being microns. If we put multiple fluorescent labels on the tubulin molecules on this long microtubule, then we can image its structure. The problem is that to get a high-resolution structure one needs to have very dense labeling. If it is not labeled you can't see the structure because no light is emitted.

However, super-localization as described above works fine when fluorophores are spatially separated. When a structure has manyfluorescent labels and theyall areallowed to emit simultaneously then the result is a blurry featureless image, because each fluorescent label is displayed as a spot with a diameter of $250 \mathrm{~nm}$, and these spots or blobs overlap. A conventional fluorescence wide-field microscope does not allow determining the structure of an object because of the fundamental blurring from diffraction. The key idea to overcome this is simply to not allow all the molecules to emit at the same time. Let us suppose that there is some mechanism which allows the emitters to be on and emitting photons part of the time, and off, or in a dark state, another

\footnotetext{
1 Biophys J. 2002; 83: 2681-2692. DOI: 10.1016/S0006-3495(02)75277 6; Biophys J. 2006; 90: 927-938 DOI:10.1529/biophysj.105.070524

2 Biophys. J. 2012, 102: 2926-2935 DOI: 10.1016/j.bpj.2012.05.015
} 


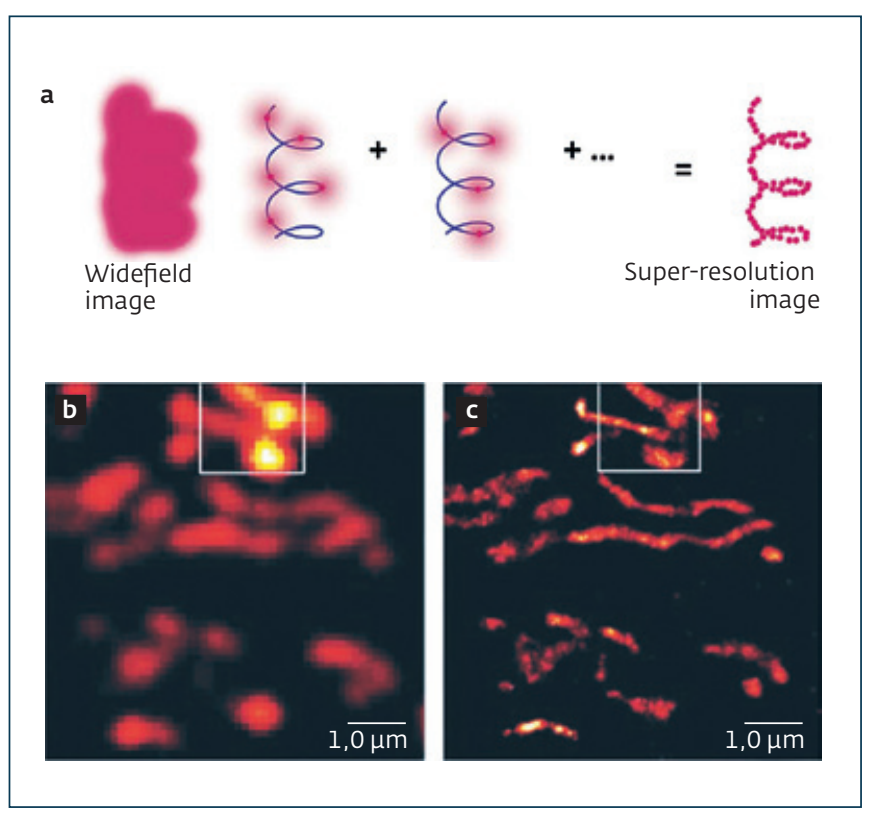

Fig.1. The key idea of super-resolution microscopy is the active control of the concentration of fluorescent labels (a); image of mitochondria in COS-7 cells using total internal reflection fluorescence microscopy (b), the same using super-resolution fluorescence microscopy (c)

part of the time. The experimenter uses this mechanism to actively control the concentration of emitting molecules to a very low level so that the point spread functions or spots do not overlap. Then, using super-localization, one can determine and record the location of each member of a small group of emitting fluorophores, while the rest of the labels remain in a dark state. Once the first subset of molecules photobleaches or enters into a dark state, another subset can be activated or stochastically turned on, and their localizations are determined and also recorded. This process is repeated many times and the resulting localizations are summed to give a super-resolution reconstruction of the underlying structure. The image is reconstructed in a pointillist fashion to show the details previously hidden beyond the diffraction limit (Fig.1) ${ }^{3}$.

So, in order to obtain a super-resolution image of an extended structure, we should only activate a few fluorophore labels at a time. This means that there must be some kind of photochemical or photophysical mechanism to allow active control over the concentration of the emitting fluorophores at a certain point in time. To solve this problem, a number of methods were proposed:

Faraday Discuss., 2015, 184: 9-36 DOI: 10.1039/c5fd00149h, Angew. Chem. Int. Ed. 2015, 54: 8067-8093 DOI: 10.1002/anie.201501949
PALM, STORM, F-PALM, PAINT and others, which allow starting with a dark molecule and then activating a small number of fluorophores. All these methods make up the SMACM (single-molecule active control microscopy) group.

However, there is another completely different approach to obtain the resolution beyond the diffraction limit - stimulated emission depletion microscopy or STED. The essence of STED from Stephan Hell is that the sample is illuminated with two different beams. The first laser beam is used to excite the sample and it gives a regular spot. The second beam uses a doughnut-shaped spot to suppress the fluorescence caused by the first beam all around its perimeter. As a result, only molecules inside the center of the doughnut are not turned off by the second beam and still fluoresce. Thus, the effective size of the fluorescent spot is reduced, and you see light only from a very small region that is less than the diffraction limit.

Both of these approaches have advantages and disadvantages.

The SMACM methods are simpler and easier to implement. But you have to collect a lot of photons in order to get a precise position which takes time. STED can run at a faster speed than STORM or PALM. On the other hand, STED is a scanning technique, one must move these two beams together fast and you don't look at the whole sample all at once. STED is a more complicated process; it requires expensive commercial equipment. In addition, a smaller group of fluorescent molecules works for STED.

To image an object we should densely label it. Sometimes it takes about a hundred labels per $250 \mathrm{~nm}$ region. Isn't the structure perturbed during the labeling?

Perturbation depends on the kind of labeling. We always ask this question, and the responsibility of each investigator consists in the most complete confirmation that the structure of the object does not change. But generally, we believe that if the label is small enough, there is no perturbation. Suppose you have a structure consisting of many monomers, for example, a microtubule. If we put a big label on each monomer it can perturb the structure, that's true. But we can put a small label on every second or every third monomer. Such selective labeling requires very good chemistry, but the shape of the resulting structure is less likely to be perturbed.

In one of our most recent papers, we studied the glycocalyx - a heavily glycosylated extramembrane compartment found on nearly every cell. Though it contains a lot of glycans or sugars sticking out of the 


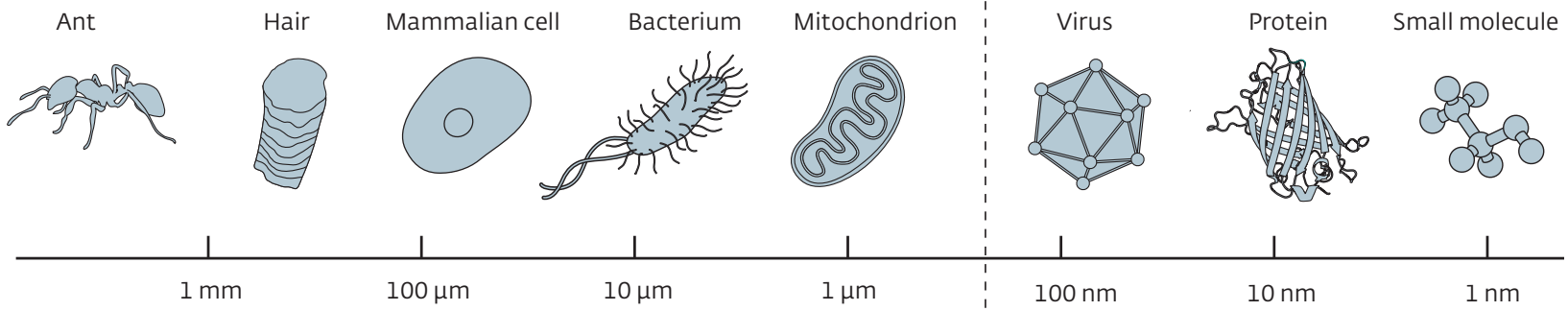

1873 Ernst Abbe defined the limit for optical microscope resolution to roughly half the wavelength of light, about 0.2 micrometer. This meant that scientists could distinguish whole cells and some organelles. However, they would never be able to discern something as small as a normal-sized virus or single proteins.

1987 William E. Moerner detected a single fluorescent molecule of pentacene in crystalline p-terphenyl.

1994 Stefan Hell published an article outlining stimulated emission depletion (STED) method. A light pulse excites all the fluorescent molecules, while another light pulse quenches fluorescence from all molecules except those in a nanometer-sized volume in the middle. Only this volume is registered.

1995 Eric Betzig suggested the conceptual foundation for single-molecule microscopy. Different flourophores - green labels, red labels and yellow labels - are excited sequentially using laser beam with different wavelength.

1997 W.E.Moerner discovered the photoactivatable green fluorescent protein (GFP). After irradiation with light of wavelength $488 \mathrm{~nm}$ the protein blinks several times and then turns off. However, the light of wavelength $405 \mathrm{~nm}$ could reactivate GFP. When the protein was reactivated, it once again fluoresced at $488 \mathrm{~nm}$.

2006

Eric Betzig presented the PALM (for PhotoActivated Localization Microscopy) method at the Frontiers in Live Cell Imaging Conference at the NIH main campus in Bethesda, Maryland. He imaged specific target proteins in thin sections of lysosomes and mitochondria?

Science, 2006, 313(5793): 1642-1645. DOI: 10.1126/ science.1127344
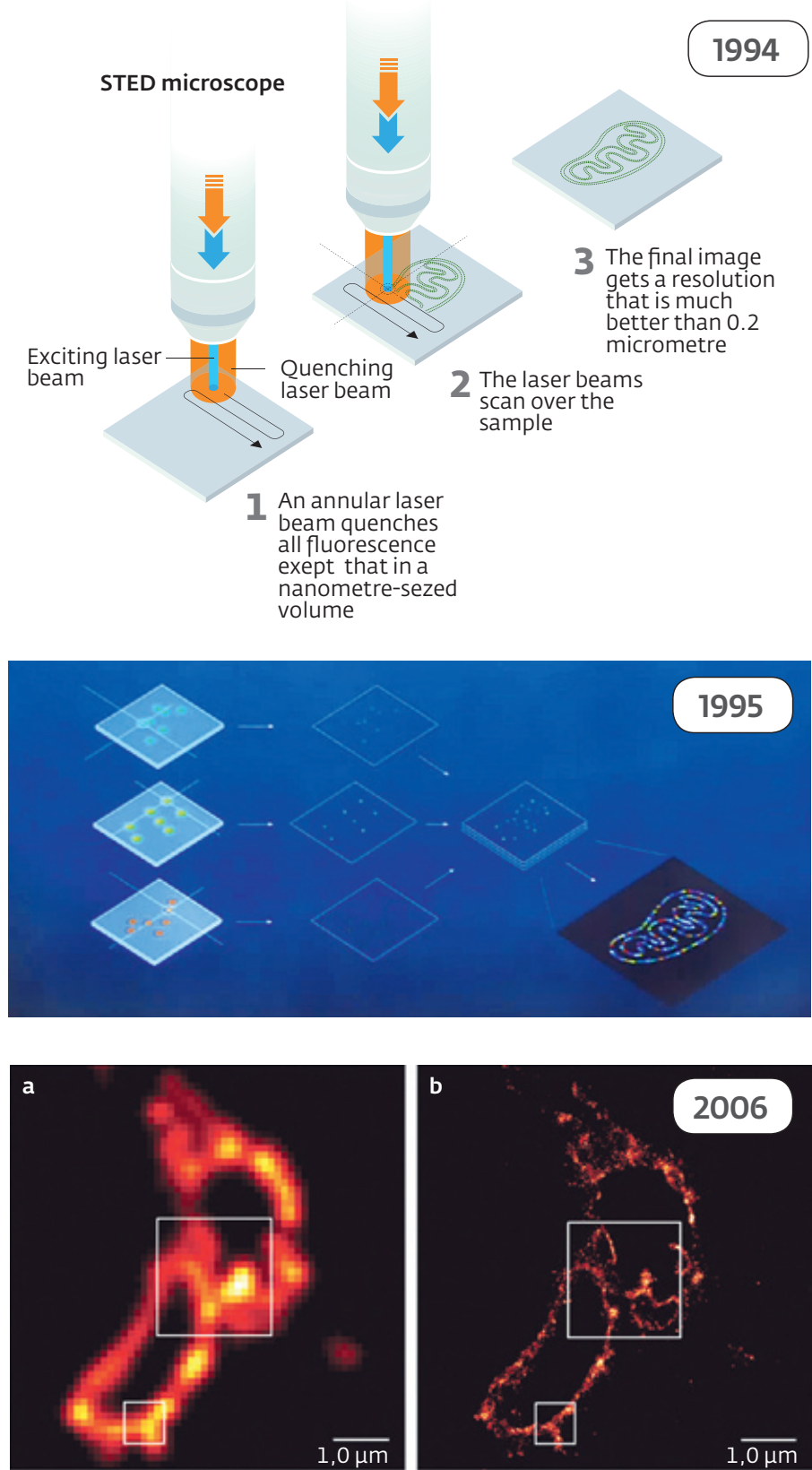
membrane, we were able to label only sialic acids using a special chemistry. And the label was just one fluorophore about $1 \mathrm{~nm}$ in size 4 . In that study, we combined quantitative super-resolution imaging with metabolic labeling and transcriptomic analysis and directly measured the height of the glycocalyx on primary tissue samples and cultured cells. We monitored its changes during the earliest steps of the oncogenic program and identified its functional role during cancer progression.

\section{Do you fix the samples in some matrix or use living cells?}

We can study both fixed and living objects. Both of these approaches have advantages and disadvantages. If you use a fixed sample nothing is moving and there is plenty of time to do the imaging. When the object is moving we have to find positions of all of the single molecules very quickly before the object changes its shape or before it moves. That means that we have to run a camera faster and faster to collect the light, or pick a structure that is not changing quickly. Some researchers have managed to complete the imaging to generate new images at a frame rate of $30 \mathrm{~Hz}$ or 30 complete images per second. Then you can see with a high resolution of how the object is moving around or changing its shape.

We generally use fixation for mammalian cells, and we usually study bacterial cells alive. But the choice depends on the questions we are trying to answer.

\section{Can you do 3D imaging?}

Yes, we can, after all, our life goes on in threedimensional space. To do the 3D imaging we change the microscope. Using a conventional microscope, you see an image on the $X Y$ plane, with one molecule forming one spot. We put additional optical components outside the microscope which allows us to encode the axial position of the emitter to the shape of its image, for example, to get a fluorescence microscope with a double-helix point spread function (DH-PSF). Now, instead of a single spot for one emitting molecule, the microscope produces two spots. These two spots revolve around a middle point thus appearing as a double helix axially and the angle of the line between the two spots depends on the z-position (Fig.2) $)^{5}$.

Now we can observe one molecule in a threedimensional volume as it moves in time, or obtain a

Dev. Cell 2019, 49: 4559. DOI: 10.1016/j.devcell.2019.04.035

5 Nano Lett. 2010, 10, 1:211-218. DOI: org/10.1021/nl903295p, Current Opinion in Structural Biology 2013, 23:778-787 DOI: org/10.1016/j. sbi.2013.07.010 three-dimensional image of the structures formed by an assembly of molecules.

How sophisticated and expensive is the equipment required for super-resolved fluorescent microscopy?

The minimum equipment is a light source, which is not necessarily, but preferably a laser; and a very good microscope objective which effectively focuses light and is capable of collecting as many photons as possible. The rest of the microscope is quite conventional: a set of filters and a camera, though even a human eye can be used to see the single spots of light from single molecules! We usually use a fancy camera to collect photons efficiently, but you can use a camera costing less than 1000 USD. This equipment is affordable for almost any lab. If you are an expert in optics you can buy all the components and put them together or you can use a commercial microscope. Some of the commercial microscopes have 3D capability, some of them don't. In any case, fluorescent microscope is cheaper than an electron microscope by a factor of 10. And if you build it yourself you can save another factor of 10 .

\section{What are your current projects?}

There are many of them: almost every student works on their own project. We use single-molecule microscopy to learn more about nature. These approaches are applied to explore protein localization patterns in bacteria, to measure structures of amyloid aggregates in cells, to define the behavior of signaling proteins in the primary cilium, to quantify photodynamics for photosynthetic proteins and enzymes, and to observe the dynamics of DNA and RNA in cells and microbes. We are interested in structures themselves that have never been observed before using super-resolution as well as the dynamics of how single biomolecules move. Other projects include cancer imaging, studying the receptors on the surface of cancer cells involved in PD1 therapy. We are working on a project producing energy collection and processing, based on molecules that are involved in photosynthesis. The energy from the sun is captured by the biosphere through photosynthetic antenna proteins, which function via integration of a set of pigments into a protein scaffold. We explore how the photophysical properties of individual pigment sites are integrated into the behavior of the complex as a whole.

Most of the current projects are related to biology however fluorescent microscopy can be successfully applied in other areas. A fluorescent image of single molecules of terrylene $\mathrm{C}_{30} \mathrm{H}_{16}$ in a spin-coated crystal of p-terphenyl could be considered as a materials science example. We 
observed an amazing thing: individual terrylene molecules are traveling inside the crystal over distances of several micrometers. Analysis of the motion by single-particle tracking and correlation methods indicates that the molecules act as nanoprobes by exploring long, thin cracklike defects with correlated orientations, defects that can be difficult to observe by other means ${ }^{6}$. Other researchers, such as Prof. Christy Landes at Rice University, are studying important polymers for chemical separation using single molecules microscopy.

It seems that your work was in close connection with the work of another Nobel laureate E. Betzig. Was it any kind of collaboration or did you develop your ideas independently?

We did not collaborate directly, though we met each other many times. We both graduated from Cornell University, although he finished a little bit after me. We worked in different parts of the department: I received my Ph.D. in experimental solid state physics, Betzig - in applied and engineering physics. But scientists always read papers of their colleagues and we followed each other's scientific achievements. I was fascinated by Betzig's work on scanning near-field microscopy over the years. He, in turn, was fascinated by our work on low-temperature highresolution microscopy of single molecules. His focus was always resolution; our focus was on science and discoveries in fundamental areas. My group discovered blinking and switching of single fluorescent proteins in 1997. And Betzig used these discoveries to achieve super-resolution. In a sense, I provided some fundamental elements: observing single molecules, blinking of fluorescent proteins, and he then used them to demonstrate PALM. It is a good example of the interdependent nature of science, even if we don't directly collaborate. He takes some ideas from our work; we take some ideas from his work.

\section{What do you think of Russian science?}

Russian science is very impressive. I don't have any direct collaboration with Russian scientists, but over many years I have had a close relationship with Andrey Naumov from the Institute of Spectroscopy RAS in Troitsk. His group has been working on low-temperature properties of single molecules for many years. I've been to Russia to attend a conference where I could learn about Andrey's work, and I have heard him and other experts speak at other meetings.

6 J. Phys. Chem. B, 2006, 110, 38: 18939-18944. DOI: org/10.1021/ jp057570b

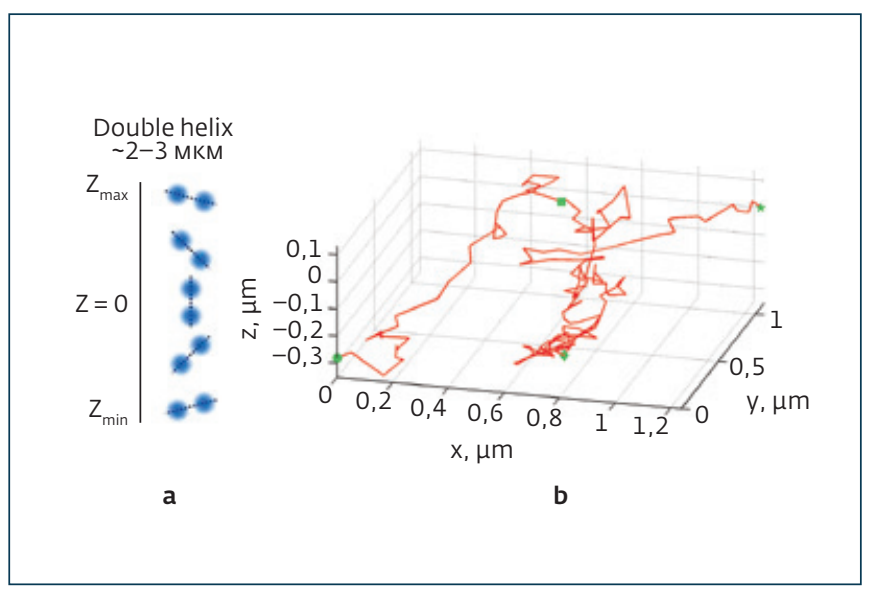

Fig.2. The scheme for obtaining a three-dimensional image using the double-helix point spread function: two points rotate around a common center as a function of the coordinate $z$ (a); trajectory of movement of a single molecule in COLO2O5 cell (b)

You received physical and engineering education and got the Nobel Prize in Chemistry. What do you consider yourself first: a physicist, an engineer or a chemist?

The important point about me is that I don't like to be put into a box. I love science in many forms. My life within science has been an evolution: exploring one field, getting excited, then exploring another field, getting excited, and so on, and finally putting the pieces together. Indeed, my first training was in physics, more specifically, my undergraduate training began in engineering, math, and physics, then I got a PhD in physics. But I was working on the problem of molecules in solids in the Physics department, so actually it was an area of chemical physics. Then, when I went into the industry at IBM, I worked in the field of physical chemistry, where I had to learn a lot and become an expert in molecules to a certain extent. Then I got an offer first from the University of California in Chemistry where I spent three years, and then moved to the Department of Chemistry at Stanford University. I teach students general chemistry and physical chemistry. Now that we are working at the interface with biology, I had to become an expert in biological aspects. It's so much fun to learn about all these different areas of science!

But in general, at a very fundamental level: you need to do what you really like. Being a scientist brings me real happiness because you get to learn how the world works.

Thank you for the fascinating talk. Professor W.E.Moerner was interviewed by N.Vasilevich 


\section{ANDREY V. NAUMOV}

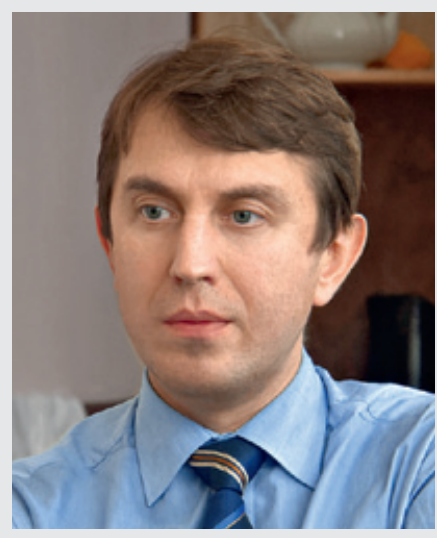

Andrey $V$. Naumov, DSC-Professor of the Russian Academy of Sciences, Head of the Department of Condensed Matter Spectroscopy and the Laboratory of Electronic Spectra of Molecules of the Institute of Spectroscopy of the Russian Academy of Sciences; Head of the Department of Theoretical Physics named after E.V.Shpolsky in Moscow Pedagogical State University, a leading Russian scientist in the field of selective laser spectroscopy and fluorescence nanoscopy.

A.V. Naumov has developed a new method of multi-parameter far-field spectral-selective diagnostics of objects with nanometer spatial resolution based on the technique of detecting zerophonon spectral lines and fluorescence images of a huge amount of single molecules of organic dyes embedded in disordered solids which serve as spectral nanoprobes. He conducted experiments clarifying the microscopic nature of the blinking luminescence effects and spectral diffusion of single semiconductor colloidal shell quantum dots, and also developed and implemented in the experiment methods for measuring the individual parameters of low-energy elementary excitations of the tunneling and vibrational types, the parameters of local fields in solids using the cryogenic single molecules spectroscopy. The developed methods and the results obtained can be used in modern applications: nanosensorics, biophysical nanodiagnostics and theranostics, quantum optics, flow cytometry, optoelectronics.

A.V. Naumov is a member of the Board of the Council on Quantum Electronics and Optics of the European Physical Society; member of the expert council of the RFBR; expert of the Russian Academy of Sciences, RSF, Federal Research Scientific Advisory Center of Expertise; member of the Bureau of the Coordinating Council of Professors of the Russian Academy of Sciences; member and chairman of the jury of various international awards; Deputy Editor-in-Chief of the journal Izvestiya RAN: Physical Series; Editor-in-chief of the journal Photonics A.V. Naumov is a laureate of a number of prestigious scientific awards, including a medal of the Presidium of the Russian Academy of Sciences for young scientists, an Academia Europaea medal, an award of the Wiley VCH publishing house, Rusnanotech Prize, and the title "Troitsk Man of the Year".

We asked Andrey V. Naumov to comment on the interview with Prof. W.E. Moerner:
"For several decades our teams happened to be closely connected with a group of Prof.Moerner by common scientific interests, which in the most general terms can be defined as "Selective laser spectroscopy of complex compounds and condensed matter". E.V.Shpolsky and his student R.M.Personov were the pioneers of this scientific field and the founders of the departments in the Institute of Spectroscopy and in the Moscow State Pedagogical University that I now lead. The culmination of the development of this direction was pioneering experiments on the detection of the single molecule spectra, conducted by prof. W. E.Moerner and his associate L. Kador in 1989 [1]. It is interesting to note that our fruitful cooperation with L. Kador, who today works at the University of Bayreuth, Germany, began more than 20 years ago and continues today. We also performed collaborative work with Prof. J.Koehler (the same University) - another co-author of Prof. Moerner. A significant part of our work on fluorescence nanoscopy with the detection of images of single quantum emitters lies directly in the field of interests of Prof. Moerner. Thus, developing a technique for detecting the spectra and images of single molecules in solid matrices at cryogenic temperatures, we were the first to carry out multi-parameter optical nanodiagnostics of solid films and significantly expand the possibilities of fluorescence nanoscopy in the areas of materials science and nanotechnology [2]. Since 2009, we were one of the first in the Russia to develop an experimental complex for such work on a domestic basis. Today we carry out experiments on a wide range of projects in the field of fluorescence nanoscopy of various materials and nanoobjects, including semiconductor quantum dots, color centers in diamond, dielectric and hybrid nanoparticles, functional organic macromolecules [3]. A number of our projects related to the development of three-dimensional nanoscopy technology are close to the current work of the Prof. Moerner group. It was in the works of W. E.Moerner 10 years ago that the idea of modifying the hardware function of a point light source using adaptive optics tools was proposed and implemented [4]. With the support of Prof. Moerner and in collaboration with our colleagues from the Samara branch of the Physical Institute named after P.N.Lebedev, we implemented this technique both at room and at cryogenic temperatures, opening the way to very interesting material science applications.

Our relationship with W.E. Moerner was significantly strengthened in connection with the holding a conference on single-molecule spectroscopy HBSM-2018 in Russia in 2018 [5]. Founded in 1987 as the leading conference on selective laser spectroscopy, HBSM remains the main platform for 
communication among specialists in fluorescence nanoscopy and single-molecule spectroscopy. The International Program Committee decided to establish an international prize and a medal named after E.V.Shpolsky, K.K.Rebane and R.I.Personov for outstanding results in the field of selective laser spectroscopy. During this visit, prof. Moerner, together with another pioneer in single-molecule spectroscopy Prof. Michel Orrit was awarded the title of Honorary Professor of the Moscow State Pedagogical University.

I would like to say that we were fantastically lucky with the opportunity to have close friendly relations with W. E.Moerner. In addition to unprecedented creativity in setting new tasks and hard work ability, I would like to note the amazing sociability and openness of Prof. Moerner as well as his versatile interests. All this contributes to the development of our scientific field, international academic cooperation and friendship between countries, which is especially important in today's difficult conditions"

1. A.V. Naumov, "Low temperature spectroscopy of organic molecules in solid matrices: from the shpolsky effect to the laser luminescent spectromicroscopy for all effectively emitting single molecules", Physics-Uspekhi, 2013, 56, 6, 605-622.

2. A.V. Naumov, A.A. Gorshelev, M.G. Gladush, T.A. Anikushina, A.V. Golovanova, J. Koehler, L. Kador, "Micro-Refractometry and Local-Field Mapping with Single Molecules", Nano Letters, 2018, 18, 10, 6129-6134

3. I.Y. Eremchev, M.Y. Eremchev, A.V. Naumov, "Multifunctional far-field luminescence nanoscope for studying single molecules and quantum dots (50th anniversary of the Institute of Spectroscopy, Russian Academy of Sciences)", PhysicsUspekhi, 2019, 62, 3, 294-303.

4. S.R.P. Pavani, M.A. Thompson, J.S. Biteen, S.J. Lord, N. Liu, R.J. Twieg, R. Piestun, W.E. Moerner, "Three-dimensional, single-molecule fluorescence imaging beyond the diffraction limit by using a double-helix point spread function", PNAS USA, 2019, 106, 9, 2995-2999.

5. A. Naumov, M. Gladush, K. Karimullin, "XIII International Conference on Hole Burning, Single Molecule, and Related Spectroscopies: Science and Applications (HBSM-2018): preface", EPJ Web Conf., 190, XIII International conference on hole burning, single molecules and related spectroscopies: science and applications (HBSM-2018), 2018, 00001.

\title{
IV Всероссийская конференция с межАународным участием
}

\section{“Аналитическая хроматография и капиллярный электрофорез"}

\begin{abstract}
Организаторы: Министерство науки и высшето образования РФ, Научный совет РАН по аналитической химии, Институт геохимии и аналитической химии им. В.И. Вернаgского РАНН, МГУ им. М.В. Аомоносова, Кубанский госуgарственный университет, ООО НТЦ “БиАСеn”
\end{abstract}

Конференция призвана обсудить вопросы, связанные с состоянием и перспективами развития аналитических возможностей методов хроматографии и капиллярного электрофореза, расширить научные связи ведущих и молодых, начинающих ученых, дать возможность ученым и практикам, работающим в области хроматографии и капиллярного электрофореза, обновить старые и установить новые контакты с коллегами. На конференции предполагается выступление ведущих специалистов в области хроматографического анализа с пленарными и ключевыми, а также с устными секционными докладами. Значительная часть оригинальных работ будет представлена в формате стендовых докладов.

\footnotetext{
В рамках конференции планируется проведение секционных, стендовых заседаний и круглых столов с участием ведущих специалистов, занимающихся развитием и применением методов и методик хроматографического анализа. Большое внимание будет уделено развитию гибридных и комбинированных методов, а также их применению в медицине, материаловедении, анализе объектов окружающей среды и др.

\section{ТЕМАТИКА:}

- теория и физико-химические основы хроматографических и электрофоретических процессов;

- селективность и эффективность разделения методами хроматографии и капиллярного электрофореза;

- состояние и перспективы инструментального обеспечения хроматографических и электрофоретических исследований;

- метрологическое обеспечение, хемометрика и обработка данных в хроматографии и капиллярном электрофорезе;

- сорбенты и материапы для хроматографии и электрофоретического анализа;

- практическое использование методов хроматографии и капиллярного электрофореза.
} 